\title{
7. Understanding housing outcomes for Indigenous Australians: what can the 2002 NATSISS add?
}

\section{Will Sanders}

\begin{abstract}
Almost a decade ago, when looking at the 1994 NATSIS, I was able to be very complimentary about what that survey could add to our understanding of housing outcomes for Indigenous Australians. That was largely because, in the housing area, the 1994 NATSIS had improved on previous census collections in two important ways: it had developed a better tenure breakdown, distinguishing between community and private rental dwellings, and it had developed an accessible and useful geographic breakdown into capital cities, other urban, and rural or remote areas. Using the 1994 NATSIS, I was able to show just how different the community and private rental tenures were for Indigenous households and, perhaps more importantly, just how different tenure profiles for these households were in rural and remote areas compared to the cities and other urban areas (Sanders 1996).
\end{abstract}

Today, it is a little more difficult to be glowingly complimentary about what the 2002 NATSISS can add to our understanding of housing outcomes for Indigenous Australians. This is not because the Indigenous survey processes have, in any way, gone backwards, but because other data collection processes, most notably the five-yearly censuses, have moved a long way forwards. Recently, I was able to undertake an analysis of housing outcomes for Indigenous households in five geographic categories of Australia ranging from major cities to very remote areas based entirely on publicly available data from the 2001 Census (Sanders 2005). I could show, even more clearly than I had been able to with the 1994 NATSISS, how different were the tenure profiles of remote areas compared to the cities and regional areas, and again how different were community and private rental. This makes it harder to argue that the 2002 NATSISS now adds so significantly to our understanding of Indigenous housing outcomes. However, it does still add some degree of understanding, and it can be used to confirm and reinforce census-based analysis.

In this paper I will reflect on the housing data from the 2002 NATSISS, drawing figures primarily from the RADL, but occasionally also quoting figures directly from ABS (2004c). The RADL contains two files, one giving characteristics of an estimated 165674 dwellings containing Indigenous households, and the other giving characteristics of an estimated 282205 Indigenous adults. When analysing housing characteristics, the predominant practice is to report figures relating to 
dwellings containing Indigenous households. However, it is also possible, and can be informative, to report by 'persons'. In what follows, I often give both sets of figures, noting in the process that the figures by 'persons' tend to accentuate the differences between tenures and geographic areas. In the first section of the paper, I look at housing tenure profiles and household size by remoteness. In the second section of the paper, I look at a range of affordability and adequacy issues analysed primarily by tenure, but also by remoteness. In the third section of the paper, I look briefly at comparisons with non-Indigenous Australians and changes over time. I conclude by reiterating that almost all of this analysis can also nowadays be done from the five-yearly census data.

Many of the tables that follow divide Indigenous households or people into remote and non-remote areas. This two-fold geography is a sub-set of the ABS's five-fold remoteness classification ranging from cities to very remote areas. The two-fold categorisation combines remote and very remote areas, on the one hand, and cities and inner and outer regional areas on the other. While not as refined as the five-fold categorisation available in the census, this two-fold categorisation is still robust enough to show major geographic differences in housing characteristics among Indigenous households and people.

\section{Housing tenure profiles and household size by remoteness}

Table 7.1 presents tenure profiles of dwellings containing Indigenous households in remote and non-remote areas in 2002. In the non-remote areas, three tenures-buying, government and private rental-each account for approximately a quarter of households, with ownership and other less significant tenures making up the last quarter of households. In the remote areas, by contrast, buying, private rental and ownership all fall away to single figure percentages, while government rental also falls away, but not quite so dramatically, to 17.1 per cent. What rises in remote areas in their place is one of the very minor tenures in non-remote areas - community rental. This tenure accounts for 49.7 per cent of dwellings containing Indigenous households in remote areas, but only 6.8 per cent in non-remote areas. Community rental is hence the dominant tenure in remote areas, while being fairly insignificant in non-remote areas. This contrast suggests just how different the housing tenure system is for Indigenous people in remote areas compared to elsewhere. 
Table 7.1. Tenure of dwellings containing Indigenous households by remoteness, 2002

\begin{tabular}{lrrr}
\hline & Remote & Non-remote & Total \\
Number 000s & 29.2 & 136.5 & 165.7 \\
\hline Owned \% & 5.9 & 11.8 & 10.8 \\
Buying \% & 7.7 & 23.2 & 20.5 \\
Government rental \% & 17.1 & 24.0 & 22.7 \\
Community rental \% & 49.7 & 6.8 & 14.4 \\
Private rental \% & 4.9 & 26.3 & 22.5 \\
Employer and other rental \% & 7.7 & 5.9 & 6.2 \\
Other \% & 7.0 & 2.0 & 2.9 \\
\hline
\end{tabular}

Source: Customised cross-tabulations from the 2002 NATSISS RADL

Some explanation of community rental may be of assistance at this point for those not familiar with Indigenous housing policy. Community rental is the product of a thirty-year government effort to improve Indigenous housing conditions at government capital expense by providing between 500 and 1000 dwellings per year through grant funding to Indigenous community organisations. While these dwellings have been government-funded the point of construction or capital expenditure, the ongoing ownership and management of them has been vested in Indigenous community organisations. These organisations have then been encouraged to charge income-related rents to cover recurrent housing costs, such as repairs and maintenance, and this has led to the label 'community rental'. The closest cousin of community rental housing within the housing tenure system is government rental, which is also provided at government capital expense, and which also charges income-related rents in the hope of covering recurrent housing costs. However, government rental in most instances is restricted to cities and smaller urban areas. It does not often extend into remote, non-urban places, where significant numbers of Indigenous people live. In these areas, community rental generally takes over the role from government rental of meeting the housing needs of those who do not seem able to do so through market processes. Sometimes government rental and community rental are together referred to as social housing.

Table 7.2, which reports housing tenure by Indigenous people aged 15 years or over (hereafter referred to as adults), accentuates the tenure difference between remote and non-remote areas shown in Table 7.1. While the figures for non-remote areas differ by only one or two per cent for any tenure category from Table 7.1, for community rental in remote areas the figure increases by almost 14 per cent so that 63.6 per cent of Indigenous adults in these areas live in community rental dwellings. The dominance of community rental among Indigenous people in remote areas thus becomes all the more stark when reported by numbers of people, rather than households. The key to this shift is different household sizes in remote and non-remote areas. 
Table 7.2. Housing tenure of Indigenous persons aged 15 years or over by remoteness, 2002

\begin{tabular}{lrrr}
\hline & Remote & Non-remote & Total \\
Number 000s & 77.1 & 205.1 & 282.2 \\
\hline Owned \% & 3.8 & 12.0 & 9.8 \\
Buying \% & 4.9 & 22.4 & 17.6 \\
Government rental \% & 13.2 & 25.4 & 22.1 \\
Community rental \% & 63.6 & 8.5 & 23.5 \\
Private rental \% & 3.4 & 24.3 & 18.6 \\
Employer and other rental \% & 5.4 & 5.6 & 5.6 \\
Other \% & 5.8 & 1.9 & 3.0 \\
\hline
\end{tabular}

Source: Customised cross-tabulations from the 2002 NATSISS RADL

Table 7.3 gives percentage distributions of household size by dwellings containing Indigenous households in remote and non-remote areas. It shows that whereas 21.2 per cent of these dwellings in remote areas have seven or more members of the household, only 5.4 per cent do in non-remote areas. Table 7.4 accentuates this difference by showing that 39.3 per cent of Indigenous adults in remote areas live in households of seven or more people, compared to 8.7 per cent in non-remote areas. Conversely, the proportions of Indigenous households containing four or fewer people, and of Indigenous people living in such households, are much higher in non-remote areas. This means tenure differences between remote and non-remote areas are accentuated when reported by Indigenous people, rather than households, due to larger Indigenous households in remote areas.

Table 7.3. Household size of dwelling containing Indigenous households by remoteness, 2002

\begin{tabular}{lrrr}
\hline & Remote & Non-remote & Total \\
Number 000s & 29.2 & 136.5 & 165.7 \\
\hline $1-2$ persons \% & 29.2 & 39.6 & 37.8 \\
3-4 persons \% & 29.2 & 38.6 & 37.0 \\
$5-6$ persons \% & 20.3 & 16.3 & 17.0 \\
7 or more persons \% & 21.2 & 5.4 & 8.2 \\
\hline
\end{tabular}

Source: Customised cross-tabulations from the 2002 NATSISS RADL

Table 7.4. Household size of Indigenous persons aged 15 years or over by remoteness, 2002

\begin{tabular}{lrrr}
\hline Number 000s & Remote & Non-remote & Total \\
\hline 1-2 persons \% & 77.1 & 205.1 & 282.2 \\
3-4 persons \% & 14.9 & 30.8 & 26.5 \\
5-6 persons \% & 24.6 & 40.7 & 36.3 \\
7 or more persons \% & 21.2 & 19.8 & 20.2 \\
\hline
\end{tabular}

Source: Customised cross-tabulations from the 2002 NATSISS RADL 
Table 7.5 presents one final set of figures relating to housing tenure profiles and remoteness. These figures are for Torres Strait Islanders living in Torres Strait, the rest of Queensland and Australia (excluding Torres Strait). The figures in this table are drawn from ABS (2004c) rather than the RADL, and are based on the number of people responding to the 2002 NATSISS (not the number of households). To ensure that the estimates are reasonably reliable, the table is restricted to just two tenure categories: owned (including buying) and rental. Islanders in the Strait show the usual heavy reliance on rental of Indigenous people in remote areas and the concomitant low levels of home buying or ownership, at just 6.2 per cent, though ABS considers this statistically unreliable. ${ }^{1}$ Islanders in the rest of Queensland show higher levels of buying and ownership and those in the rest of Australia, even higher still. We should note in passing here that were this third geographic category to be defined exclusively, as Australia excluding Queensland, (rather than overlapping with the second category and hence including Islanders in the rest of Queensland again), then clearly the level of home buying and ownership among this group of Islanders would be significantly higher again.

Table 7.5. Housing tenure of Torres Strait Islander persons aged 15 years and over by area, 2002

\begin{tabular}{lrrr}
\hline & Torres Strait & Rest of Queensland & Australia (excluding Torres Strait) \\
Number Ooos & 3.6 & 13.0 & 26.2 \\
\hline Owned \% & $6.2^{* *}$ & $20.9^{*}$ & 34.9 \\
Rental \% & $84.6^{*}$ & 79.1 & 63.8 \\
\hline
\end{tabular}

Source: ABS (2004c: Table 23)

\section{Affordability and adequacy issues by tenure and remoteness}

Back in 1996, using the 1994 NATSISS, the second set of issues I was able to explore was the affordability and adequacy of different housing tenures including, at times, owning and buying, as well as community, government and private rental. This exploration bore out the usefulness-indeed, the indispensability - of the distinction between community and private rental, as these are not only very different tenures in terms of their geographic distribution but also in terms of their affordability and adequacy characteristics.

Table 7.6 confirms, yet again, the vast differences in rents between community and private rental, with mean weekly rentals of $\$ 66$ and $\$ 152$ respectively. Government rental, with a mean rent of $\$ 87$ per week, is a little more expensive than community rental but considerably less expensive than private rental.

${ }^{1}$ One asterisk indicates that the estimate should be used with caution because it has a relative standard error of between 25 and $50 \%$. Two asterisks indicate that the estimate has relative standard error of greater than $50 \%$ and the ABS generally considers it unreliable. Clearly estimating even a two-fold distinction for a population group of only 3600 is pushing the NATSISS to its methodological limits. 
Table 7.6. Weekly rents (in 2002 \$) of dwellings containing Indigenous households by tenure, 2002

\begin{tabular}{lrrr}
\hline & Community rental & Government rental & Private rental \\
\hline Mean & 66 & 87 & 152 \\
Median & 60 & 80 & 145 \\
\hline
\end{tabular}

Source: Customised cross-tabulations from the 2002 NATSISS RADL

Table 7.7 suggests there is, however, a downside to the inexpensiveness of community rental in terms of dwelling adequacy. It presents data from the 2002 NATSISS showing community rental dwellings as being reported most often (at $54.7 \%$ ) as having structural problems and least often (at $57.6 \%$ ) as having repairs and maintenance carried out in the last twelve months. Government and private rental were reported to be substantially better on both these adequacy measures and dwellings that were owned or being bought were better still.

A third measure of housing adequacy has been constructed by the ABS by comparing numbers of people and bedrooms in a dwelling against the Canadian National Occupancy Standard (CNOS). ${ }^{2}$ On this measure too, community rental comes out as the least adequate tenure, with 34.4 per cent of its dwellings requiring additional bedrooms, compared to 13.8 per cent in government rental, 11.6 per cent in private rental and single figure percentages in dwellings that are owned or being bought. To a large extent, these figures for requiring additional bedrooms are a reflection of household size and, in the fourth line of Table 7.7, I give the mean household size for dwellings containing Indigenous households by tenure. Community rental, at 4.6, has a distinctly larger mean household size than the other tenures, none of which have means above 3.6 people per household.

The fifth line of Table 7.7 provides a housing affordability measure, which is perhaps a little more sophisticated than just rent paid. This is the proportion of households paying more than 25 per cent of their income in rent or mortgage. On this measure, community rental $(16.0 \%)$ is again a bit more affordable than government rental $(22.2 \%)$ and a lot more affordable than private rental $(50.2 \%)$. Also, buying is actually more affordable than all three rental tenures, although buyers may of course have non-mortgage costs, like rates, that renters do not. Furthermore, affordability for buyers can depend greatly on where they are in the repayment cycle, so comparisons between buyers and rental tenures are not straightforward. The most important figure to emerge from this fifth line of Table 7.7 is, I would argue, that 50.2 per cent of Indigenous households in private rental pay more than 25 per cent of their household income in rent. Whereas community rental appears to be an inexpensive tenure with some adequacy issues for Indigenous households, private rental appears to be a tenure category with some quite significant affordability issues.

2 The CNOS is explained at explanatory notes 49 and 50 in ABS (2004c). 
From the sixth line, Table 7.7 presents more fine-grained housing adequacy measures from the 2002 NATSISS relating to household facilities; such as whether a dwelling has a working stove, washing machine or toilet, and adequate kitchen bench and cupboard space. Although the proportions of dwellings containing Indigenous households which have these facilities are generally quite high, there are instances where they drop away. In all instances, bar one, it is community rental dwellings that most frequently do not have these facilities. The three instances where figures drop below 90 per cent in this part of Table 7.7 are all in community rental dwellings; having a working fridge $(89.9 \%)$, a working washing machine $(81.1 \%)$, and having adequate kitchen cupboard and bench space $(76.5 \%)$. The last line of Table 7.7 shows major differences between tenures in having a working telephone in the dwelling, with less than half of community rental dwellings doing so.

Table 7.7. Adequacy and affordability characteristics of dwellings containing Indigenous households by tenure, 2002

\begin{tabular}{|c|c|c|c|c|c|}
\hline & $\begin{array}{r}\text { Community } \\
\text { rental }\end{array}$ & $\begin{array}{r}\begin{array}{r}\text { Government } \\
\text { rental }\end{array} \\
\end{array}$ & $\begin{array}{r}\text { Private } \\
\text { rental }\end{array}$ & Buying & Owned \\
\hline Number 000s & 23.8 & 37.7 & 37.3 & 33.9 & 17.8 \\
\hline Has structural problems \% & 54.7 & 41.8 & 33.5 & 22.5 & 22.3 \\
\hline Repairs and maintenance carried out \% & 57.6 & 64.5 & 61.6 & 72.0 & 63.1 \\
\hline Requires additional bedrooms $\%$ & 34.4 & 13.8 & 11.6 & 5.6 & 6.1 \\
\hline Mean household size & 4.6 & 3.4 & 3.1 & 3.6 & 3.0 \\
\hline $\begin{array}{l}\text { Pays }>1 / 4 \text { of household income in } \\
\text { rent/mortgage } \%\end{array}$ & 16.0 & 22.2 & 50.2 & 14.1 & - \\
\hline Has working stove/oven $\%$ & 91.1 & 99.1 & 98.3 & 99.8 & 97.3 \\
\hline Has kitchen sink \% & 97.7 & 100.0 & 99.1 & 99.6 & 98.7 \\
\hline $\begin{array}{l}\text { Has adequate kitchen cupboard/ bench } \\
\text { space \% }\end{array}$ & 76.5 & 81.2 & 89.1 & 91.9 & 94.9 \\
\hline Has working refrigerator $\%$ & 89.9 & 96.8 & 97.6 & 99.9 & 99.9 \\
\hline Has working washing machine \% & 81.1 & 90.4 & 92.6 & 98.1 & 98.3 \\
\hline Has working bath/shower \% & 97.9 & 99.2 & 99.5 & 100.0 & 99.5 \\
\hline Has laundry tub \% & 96.7 & 96.9 & 94.7 & 98.1 & 97.5 \\
\hline Has working toilet $\%$ & 97.1 & 99.2 & 99.4 & 99.8 & 99.8 \\
\hline Has working telephone $\%$ & 47.1 & 72.7 & 80.9 & 95.6 & 94.3 \\
\hline
\end{tabular}

Source: Customised cross-tabulations from the 2002 NATSISS RADL

Table 7.8 reports the top five of these adequacy and affordability measures by Indigenous adults living in different tenures. This reporting tends to accentuate the differences between community rental and the other four tenures compared to reporting by dwelling. For example, the percentage for dwellings requiring additional bedrooms in community rental increases from 34.4 per cent when reported by dwelling to 51.0 per cent when reported by 'persons', while the comparable shift for private rental is from 11.6 to 18.2 per cent. These shifts need not concern us greatly here, as reporting housing adequacy and affordability characteristics as if they attach to people is sometimes a bit strained. Also, in the 2002 NATSISS, this information was generally obtained from a single household spokesperson, so is probably best reported on a household basis. 
Table 7.8. Housing adequacy and affordability characteristics of Indigenous persons aged 15 years or over by tenure, 2002

\begin{tabular}{|c|c|c|c|c|c|}
\hline & $\begin{array}{r}\text { Community } \\
\text { rental }\end{array}$ & $\begin{array}{r}\text { Government } \\
\text { rental }\end{array}$ & $\begin{array}{r}\text { Private } \\
\text { rental }\end{array}$ & Buying & Owned \\
\hline Number 000s & 66.4 & 62.2 & 52.4 & 49.6 & 27.5 \\
\hline Has structural problems \% & 62.2 & 42.6 & 34.5 & 21.4 & 23.7 \\
\hline Repairs and maintenance carried out \% & 56.4 & 66.2 & 60.9 & 72.9 & 64.7 \\
\hline Requires additional bedrooms \% & 51.0 & 20.5 & 18.2 & 9.8 & 10.3 \\
\hline Mean household size & 5.9 & 4.0 & 3.5 & 3.9 & 3.4 \\
\hline $\begin{array}{l}\text { Pays }>1 / 4 \text { of household income in } \\
\text { rent } / \text { mortgage } \%\end{array}$ & 8.6 & 17.2 & 44.9 & 11.4 & - \\
\hline
\end{tabular}

Source: Customised cross-tabulations from the 2002 NATSISS RADL

Of more substantial interest is that these housing adequacy and affordability measures from the 2002 NATSISS can also be reported by remote and non-remote areas, as in Table 7.9. Given the very different geographic distribution of the tenures, it is not surprising that this division also shows substantial adequacy and affordability differences. Table 7.9 shows that 49.9 per cent of dwellings containing Indigenous households in remote areas have structural problems compared to 31.9 per cent in non-remote areas. And 32.9 per cent in remote areas require additional bedrooms compared to 9.7 per cent in non-remote areas. Conversely, only 10.4 per cent of Indigenous households in remote areas pay more than 25 per cent of their household income in rent or mortgage payments compared to 26.4 per cent in non-remote areas. Further down Table 7.9 we can also see, for example, that 89.6 per cent of dwellings containing Indigenous households in remote areas have a working refrigerator, compared to 98.4 per cent in non-remote areas, while 50.3 per cent in remote areas have a working telephone compared to 83.4 per cent in non-remote areas. Table 7.10, like Table 7.8 for tenures, reports the top five of these adequacy and affordability measures by Indigenous persons, rather than dwellings. 
Table 7.9. Adequacy and affordability characteristics of dwellings containing Indigenous households by remoteness, 2002

\begin{tabular}{lrr}
\hline Number 000s & Remote & Non-remote \\
\hline Has structural problems \% & 29.2 & 136.5 \\
Repairs and maintenance carried out \% & 49.9 & 31.9 \\
Requires additional bedrooms \% & 51.8 & 65.9 \\
Mean household size & 32.9 & 9.7 \\
Pays > 1/4 of household income in & 4.4 & 3.3 \\
rent/mortgage \% & 10.4 & 26.4 \\
Has working stove/oven \% & & 99.1 \\
Has kitchen sink \% & 89.0 & 99.4 \\
Has adequate kitchen cupboard/bench & 96.5 & 88.4 \\
space \% & 75.9 & 98.4 \\
Has working refrigerator \% & & 94.3 \\
Has working washing machine \% & 89.6 & 99.6 \\
Has working bath/shower \% & 80.9 & 96.9 \\
Has laundry tub \% & 96.1 & 99.7 \\
Has working toilet \% & 93.5 & 83.4 \\
Has working telephone \% & 94.9 & \\
\hline
\end{tabular}

Source: Customised cross-tabulations from the 2002 NATSISS RADL

Table 7.10. Housing adequacy and affordability characteristics of Indigenous persons aged 15 years or over by remoteness, 2002

\begin{tabular}{lrr}
\hline & Remote & Non-remote \\
Number 000s & 77.1 & 205.1 \\
\hline Has structural problems \% & 58.4 & 32.5 \\
Repairs and maintenance carried out \% & 51.9 & 66.7 \\
Requires additional bedrooms \% & 50.3 & 14.9 \\
Mean household size & 5.8 & 3.7 \\
Pays > 1/4 of household income in & 7.1 & 19.9 \\
rent/mortgage\% & & \\
\hline
\end{tabular}

Source: Customised cross-tabulations from the 2002 NATSISS RADL

Tables 7.7 to 7.10 all show that housing adequacy issues are much more prevalent in remote areas and community rental, while affordability issues are much more prevalent in non-remote areas and private rental. This contrast is now a well established theme in discussions of Indigenous housing need based on census analysis (Neutze, Sanders \& Jones 2000). It should also be noted, in this regard, that the measures in lines three to five of tables 7.7 to 7.10 can be-and have, in recent times, increasingly been - constructed from census data (Jones 1994, 1999; NCSAGIS 2003). If these measures are seen as sufficient for understanding the basic adequacy and affordability characteristics of Indigenous housing, by tenure and remoteness, then the census tells us essentially what we need to know. 


\section{Comparisons with non-Indigenous Australians and over time}

ABS (2004c) draws on the 2002 GSS to construct comparisons between the tenure profiles of Indigenous and non-Indigenous people aged 18 years and over. The findings are reproduced in Table 7.11, although I have left out the figures combining remote and non-remote Indigenous people on purpose. These seem to me to combine two such disparate groups (in terms of their housing tenure characteristics) that they actually obscure, rather than clarify, the situation. Perhaps more importantly, the non-indigenous estimates only refer to non-remote areas - that is, where the GSS was conducted.

Table 7.11 usefully reminds us that, whatever the differences between the housing characteristics of Indigenous people in remote and non-remote areas, the differences between Indigenous people in non-remote areas and non-Indigenous people are just as great. Only 12.4 per cent of Indigenous people aged 18 years or over in non-remote areas live in houses that are owned by an occupant, compared to 38.5 per cent of non-Indigenous people. And the percentages for living in houses that are being bought are 21.0 and 34.6 respectively. Conversely, Indigenous people in non-remote areas rely far more heavily than do non-Indigenous people on both government rental (24.4 per cent compared to 3.8 per cent) and other-mainly private - rental (29.8 per cent compared to 19.9 per cent). Meanwhile, the housing tenure characteristics of Indigenous people in remote areas are so different from those of non-Indigenous people as to not really bare comparison at all.

Table 7.11. Housing tenure characteristics of Indigenous and non-Indigenous persons aged 18 years or over, 2002

\begin{tabular}{|c|c|c|c|}
\hline & Indigenous remote & Indigenous non-remote & Non-Indigenous non-remote \\
\hline Number 000s & 69 & 182 & 14354 \\
\hline Owned \% & 4.0 & 12.4 & 38.5 \\
\hline Buying \% & 4.6 & 21.0 & 34.6 \\
\hline Government rental \% & 12.6 & 24.4 & 3.8 \\
\hline Community rental \% & 64.3 & 9.3 & 0.6 \\
\hline Other renter \% & 8.4 & 29.8 & 19.9 \\
\hline
\end{tabular}

Source: ABS (2004c: Table 4)

Table 7.12 is again taken from ABS (2004c) and gives changes in the housing tenure characteristics of Indigenous adults from the 1994 NATSISS to the 2002 NATSISS. The biggest change is an 11.2 per cent drop in Indigenous people in government rental, from 33.3 to 22.1 per cent. This seems a surprisingly large drop, which needs further investigation. It probably reflects a quickly growing Aboriginal population at a time when the public housing stock is only growing very slowly or, relative to total housing stock, is perhaps in decline. However, it may also reflect some specific developments in Indigenous housing policy in particular States and Territories, where under recent inter-governmental 
agreements it is possible that some Indigenous-specific public rental housing is being reclassified as community rental, or at least new investment in Indigenous-specific housing is moving in this direction. This seems to me something that will be worthwhile looking into when the 2006 Census becomes available and we have a much larger set of data spanning 10 years and three time points which distinguishes between government, community and private rental. However, it can be noted in passing, in a preliminary fashion, that when measured by dwelling numbers, the proportion of Indigenous households in public housing does appear to have been dropping since 1986 (Sanders 1996: 108).

The other major changes over time evident in Table 7.12 are a 6 per cent increase in people in dwellings that are being bought, a 5.6 per cent increase in people in community rental dwellings and 4.6 per cent increase in people in other, mainly private, rental dwellings. I think all these changes in tenure percentages should be treated with some caution, not least because they could partly be explained by a significant drop in the proportion of people for whom no housing tenure information was obtained from the 1994 NATSISS $(7.6 \%)$ compared to the 2002 NATSISS (3.8\%). These 'not stated' figures are not given in ABS (2004c), but are calculated in the last line of Table 7.12 by simply subtracting from 100 the percentage sum of the tenures given. Again, I would argue that the 2006 Census should give us some greater ability to look more reliably at tenure changes among Indigenous people and households, at least back to 1996.

Table 7.12. Housing tenure characteristics of Indigenous persons aged 15 years or over, 1994 and 2002

\begin{tabular}{|c|c|c|}
\hline & 1994 & 2002 \\
\hline Number 000s & 214.6 & 282.2 \\
\hline Owned \% & 10.9 & 9.7 \\
\hline Buying $\%{ }^{a}$ & 10.8 & 16.8 \\
\hline Government rental $\%^{\text {a }}$ & 33.3 & 22.1 \\
\hline Community rental $\%^{a}$ & 18.7 & 24.3 \\
\hline Other rental $\%^{a}$ & 18.7 & 23.3 \\
\hline Housing tenure not stated? $\%^{a}$ & 7.6 & 3.8 \\
\hline
\end{tabular}

a. The difference between 1994 and 2002 is statistically significant at the $5 \%$ level. Source: ABS (2004c: Table 6)

\section{Conclusion}

One recurring theme of this paper is that most housing analysis that can be done from the Indigenous-specific surveys can also nowadays be done from the five-yearly national census. Indeed, the census often gives a better tenure and geographic breakdown than surveys can. What the Indigenous-specific surveys have added, in comparison to the census, is some greater detail relating to housing adequacy measures. However, basic adequacy measures can also be derived from the census. So the answer to the question posed in the subtitle, 'What can the 
2002 NATSISS add?' is, in fact, 'not all that much'. The 2002 NATSISS confirms census analysis rather than taking it much further. Indeed, in the last section of the paper above, I have suggested that the findings from the 1994 and 2002 Indigenous-specific surveys relating to changes in housing tenure over time among Indigenous people should be treated with some caution and that it may be best to wait until the 2006 Census to work on this topic. Censuses are clearly the pre-eminent data sources for studying Indigenous housing outcomes, but the 2002 NATSISS can offer some insights on adequacy issues. 